\title{
Emulating Natural Morphology in Anterior Crown Fractures: Two Years Follow-up Report
}

\author{
Bora korkut* \\ Department of Restorative Dentistry, Marmara University, Turkey
}

Submission: September 05, 2017; Published: October 25, 2017

*Corresponding author: Bora Korkut, Marmara University, Dentistry Faculty, Restorative Department,Istanbul, Turkey, 34746, Tel: +90532 5911560; Email: bora.korkut@marmara.edu.tr

\begin{abstract}
Patients may suffer from undesirable aesthetic problems due to color, shape and structural or position abnormalities of anterior teeth. Crown fractures are one the most common reasons of these aesthetic complaints especially in young patients. Creating a conservative as well as powerful restoration against destructive occlusal forces while emulating similar outlook to natural dental tissues is the main objective of treatment of such cases. Direct composite resin restorations are one of the best possible treatment options for the anterior crown fractures. As the dental materials and techniques develop, the clinicians start to learn the physical and optical properties of these materials and use them with proper techniques to create more natural alike as well as long lasting restorations. These restorations are no longer named as 'day savior fillings' today but are called minimally invasive, functional and long lasting 'direct aesthetic restorations' that perfectly emulate natural dental tissues even in anterior area. This article illustrates how to perform a minimally invasive, long lasting, functional and natural alike direct aesthetic restorations in a single visit.

Keywords: Crown fracture; Direct aesthetic restorations; Emulating natural tissues
\end{abstract}

\section{Objective}

Performing a minimally invasive, long lasting, functional and natural alike direct composite resin restorations in a single visit.

\section{Introduction}

Aesthetic restoration of lost dental tissues of anterior teeth is a crucial challenge in restorative dentistry. Patients may suffer from undesirable esthetic problems due to color, shape, structural and position abnormalities of anterior teeth. Creating more conservative as well as more powerful restorations against occlusal, lateral and protrusive forces and emulating similar outlook to natural dental tissues is the main objective of up-todate, contemporary dentistry [1]. An increasing number of dentists prefer minimal invasive and less time-consuming treatment options; as direct resin restorations compared to indirect ceramic restorations for the anterior dental aesthetics [2]. In order to create more natural-looking restorations, clinicians must learn and understand the physical properties of the dental tissues and restorative materials that they use and also interactions of these tissues and materials with light [3]. Various dental materials and techniques have been coming on the scene to improve both functional and aesthetic quality of the restorations. However a few of the esthetic resin materials on the market meet the expectant. The ones having such properties such as simplicity, structural stability, surface polish ability, masking discolorations, surface texturing and simulating natural dental color parameters such as hue, value and chrome are one step ahead [4,5].

\section{Clinical considerations}

In this report complex crown fractures due to dental trauma on maxillary right central and lateral incisors were corrected with minimally invasive direct composite resin restorations by using layering technique in a single appointment. The composite resin material used in this case study is a recently developed resin based restorative material, Estelite Asteria (Tokuyama, Japan) designed for emulating natural dental tissues.

\section{Case Report}

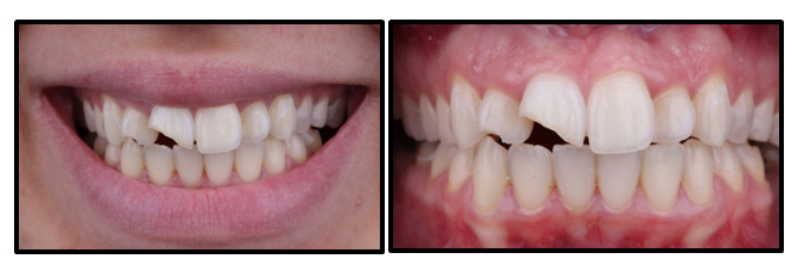

Figure 1,2: Initial.

17 years old female patient applied to the clinic with aesthetic complaints due to dental trauma. He had direct trauma to the maxillary incisors a year ago and had no pain or any other symptoms. According to the intraoral examination complex crown 
fractures on maxillary right central and lateral incisors were determined (Figure 1,2).

According to the radiographic and vital metric analysis the injured teeth were considered as vital. The periodontal tissues were healthy and oral hygiene was in good condition. The patient' $\mathrm{s}$ age and the examinations were both taken into consideration and a conservative approach, minimal invasive direct aesthetic resin restorations were considered as the treatment plan.

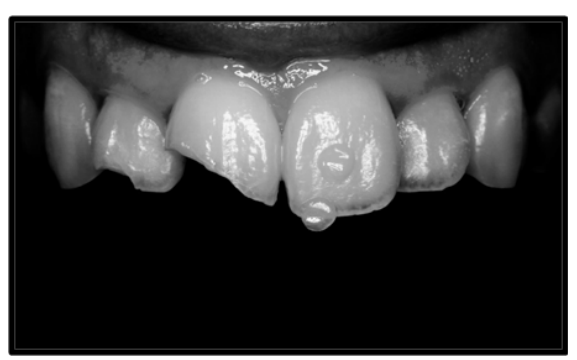

Figure 3: Shade selection.

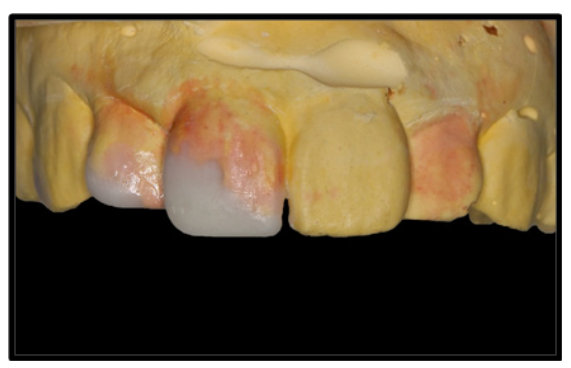

Figure 4: Wax-up restorations for silicone index.

Shades selected by using macro dental photography and composite shade samples which are also known as the 'Button Technique. Most appropriate body and translucent shade samples of Estelite Asteria (Tokuyama, Japan) were selected and located on the crown of left central incisor. The body shades were located on the mid-third and the translucent shades were located on the incisal-third of the crown. Then a macro photograph was taken from the labial view by using a professional camera set designed especially for dental photography. The set consist of a body (D700), a macro lens (Macro 100mml), a macro twin flash (MT24EX Macro Twin Late Flash), two-sided reflectors and a dual flash bracket mount (Novo Flex Unset). The picture taken was processed in a computer software program called Adobe Photoshop CC (Photoshop CC, Adobe Systems Software). A processed black and white form of the photograph was used to decide the translucent shade. Another processed copy on which contrast was increased and brightness was decreased, was used to decide the body shade (Figure 3). A1B and NE shades (Estelite Asteria, Tokuyama, Japan) were selected. Temporary restorations were prepared for the cracked teeth on a cast model and silicone impression was taken to create a palatal silicone index (Figure 4). Rubber dam was applied on maxillary incisors and canines for maximum isolation (Figure 5). 45 degree deep beveling were done on both incisors to cover the crack lines as minimally invasive preparations (Figure 6). One bottle universal adhesive agent (Bond Force II, Tokuyama, Japan) was used with selective etching. The translucent shade composite resin, NE shade, was used to create the palatal enamel wall. The resin was placed on incisallt on the silicone index and refined by using a composite brushed wetting resin. Then the resin and the silicone index were placed intraoral on the palatal surface of the teeth and polymerized. The index removed and palatal enamel wall was created (Figure 7).

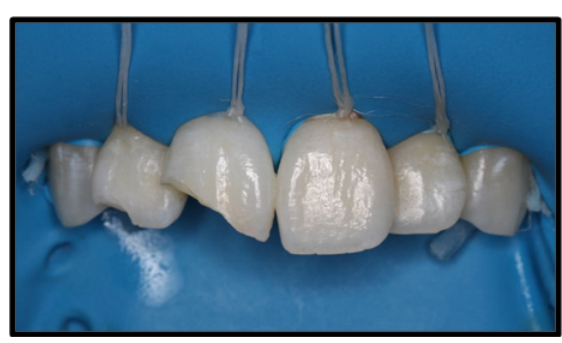

Figure 5: Isolation.

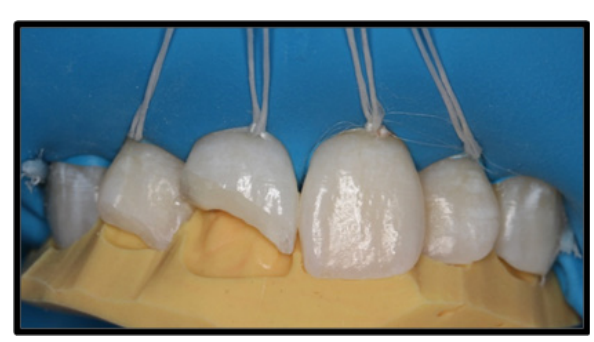

Figure 6: Minimal invasive preparations.

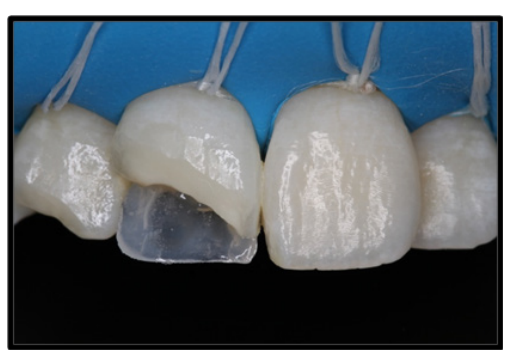

Figure 7: Palatal wall.

The same resin was used to create marginal enamel walls of the restorations by using kidney-shaped metal matrix bandstand wedges (Figure 8). Body shade composite resin, A1B shade, was used to emulate dentin tissue (Figure 9). Labial surface was restored by using the translucent shade resin (NE) to create the surface enamel layer (Figure 10). In order to avoid overcontouring, composite brush was used with the wetting resin for layering. The surface structure was also created in final surface layering step. The resin used for emulating the enamel surface layer was applied in 3 steps; medial third, distal third and middle third, so that creating the surface grooves, ridges and also incisal notches while layering. The irregular scratches on the surface were emulated by using the composite brush gently without wetting resin (Figure 11). 


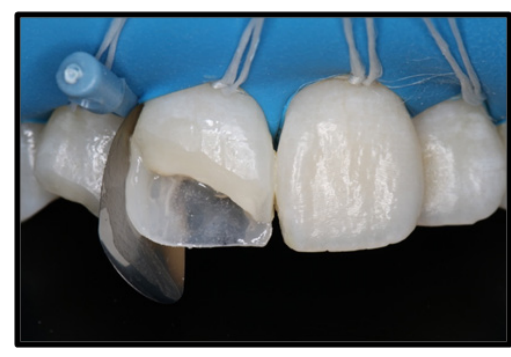

Figure 8: Marginal wall.

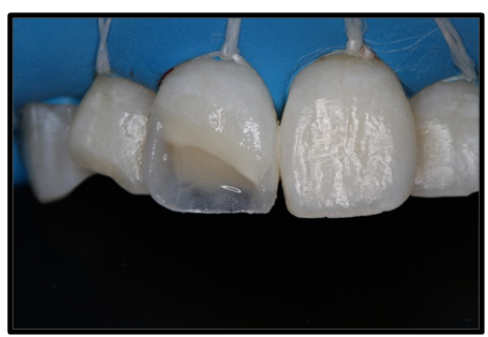

Figure 9: Body shade layering.

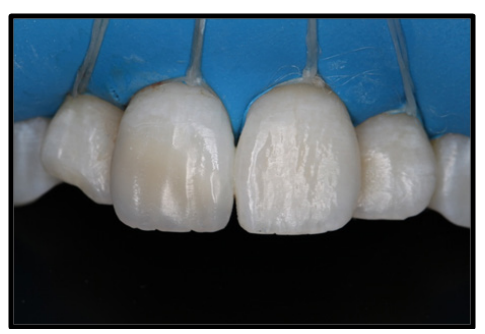

Figure 10: Translucent shade layering.

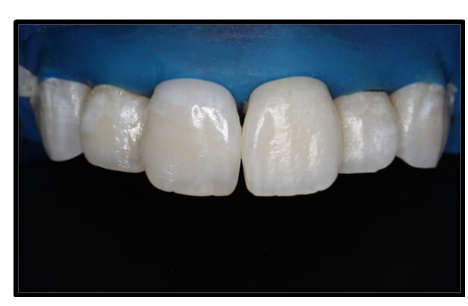

Figure 11: Macro and micro surface textures.

After polymerization of the last layer, glycerin (Air Barrier, GC, Japan) was applied to whole the restoration surfaces and polymerized for 40 seconds to eliminate the oxygen inhibition layer. The surface cleaned with water spray and dried with air spray. Marginal adaptations and removal of excessive resins were done by a \#12 lancet, a fine-grained composite polishing disk (Soflex, 3M, Japan) and interface sandpapers (Epitex, GC, Japan). The labial surface was polished by using only a fine-grained spiral rubber disc (Twist-Dia, light blue) in low speed and in dry condition (Figure 12,13).

The patient was informed about the oral hygiene and informed for recalls for every 6 months (Figure 14).

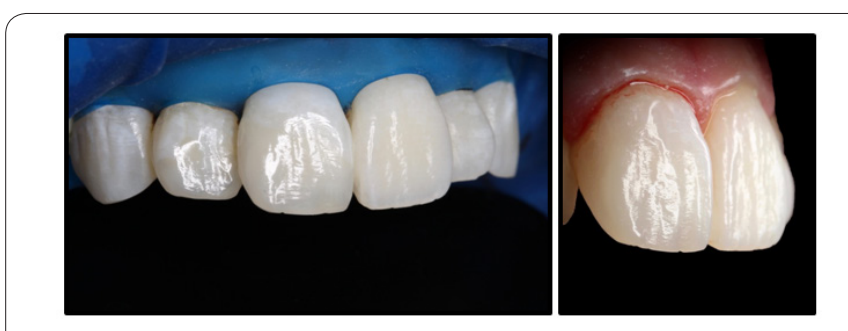

Figure 12,13: Detailed polishing.

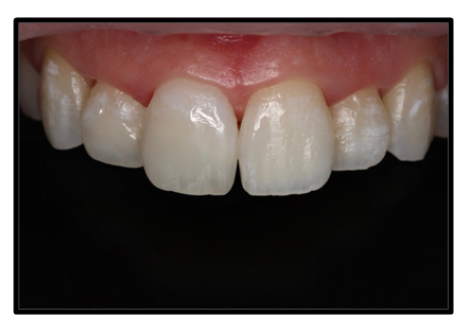

Figure 14: Final, just after the restorations.

At 2years recall no sensitivities, fractures, secondary caries lesions were detected on both the teeth and the restorations. Also no discolorations or demarcation lines were detected (Figure $15,16)$.
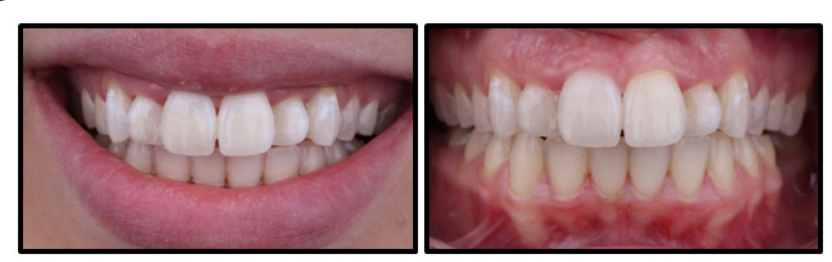

Figure 15,16: Two years follow-up.

On the other hand the micro surface morphology on the central incisor, created with brush touches while layering, was barely may observed. The patient reported that the restorations were fully functional during the time and he was also very satisfied with the aesthetic result. Oral hygiene and periodontal health were also in good condition (Figure 17).

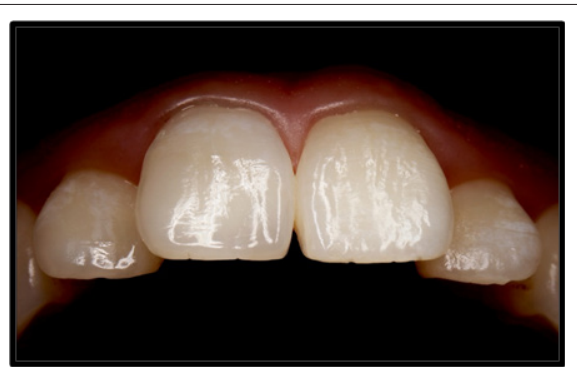

Figure 17: Two years follow-up, the surface texture.

Considering all, in 2 years follow-up the structural integrity, the color stability as well as the aesthetic outlook of the restorations was considered as satisfactory. The patient was called for further follow-ups. 


\section{Discussion}

Ever increasing aesthetic demands of the patients require better dental materials and application techniques and also more clinical experience and knowledge. Natural-looking as well as functional and stable dental restorations may only be created only with the combination of these headlines. Natural dental tissues demonstrate translucency, opalescence, and fluorescence that must be imitated by the chosen restorative material in order to emulate the natural $[6,7]$. Especially translucency is recently accepted to have a key role in shade match of the restorative materials with natural dental tissues. Translucency is defined as the amount of light that passes through the dental tissues and may vary according to one of the parameters of color, value [8]. If the value of a tooth or dental material is high, lighter reflect from the surface, resulting in low translucency [9]. Taken this into consideration, some dental manufacturers have developed some new generation of aesthetic composite resins to emulate the natural dental tissues better than ever.

In the case presented a recently produced Estelite Asteria (Tokuyama, Japan) was used as the composite resin material which has supra-nano inorganic spherical fillers. Although this resin has an advantage for using as two-step layering, in this case conventional three-step layering was used to mimic the natural dental tissue layers. The composite brush manipulation was very easy and effective while layering as the consistency of the resin was soft enough. It is a fact that the composite layering procedures under reflector light takes much longer time that might be a problem. But the working time of the shades of this resin was also long enough. The polymerizing time for the shades used in this study was 10 seconds that is an advantage for the clinician. The natural surface morphology was emulated with gentle brush touches while surface layering. As the method used for layering depends on not creating over-contouring, the polishing procedures for restoration surfaces only done by a fine grained spiral polishing disc (Twist Dia, light blue). The surface texture created by composite brush hits could only be protected by using this polishing procedure [10]. This polishing material also creates a very shiny surface that is also very resistant to discolorations. Smooth adaptation between resin and dental tissues and having no micro-leakage due to the enhanced physical properties of the resin such as low polymerization shrinkage may describe having no sensitivities or secondary caries at 2 years recall [11]. As the correct indication of the case is an indispensable condition for direct anterior resin restorations, the stability of the restorations depends on having no devastating occlusal forces. The restorations were fully functional during the 2 years time and had no fractures as a result of that [12]. The enhanced fracture resistance of the composite resin might also positively affect the strength of the restorations. Also the glycerin (Air Barrier, GC, Japan) used for enhancing the physical properties of the surface layer made a positive effect on creating a more resistant surface layer to potential fractures and discolorations [13]. The loss in micro surface morphology on the central incisor that was created with brush touches may be related to the erosive or abrasive pattern of patient's diet and brushing style. It may be due to the surface roughness of the restoration which is related to the physical properties of the resin used. However that loss was insignificant for the aesthetic outlook in speaking distance. The patient was very satisfied with the durability, aesthetic outlook and especially the color harmony and gloss of the restorations. The specific spherical fillers and enhanced optical properties of the resin [14], the button technique used for selection of the shades [15], overcontour less layering technique $[8,16]$ and detailed polishing procedures [17] are possibly played the key roles in this aesthetic outcome.

For years the anterior direct resin restorations compared to the indirect veneers and accepted as a loser in general. They were blamed as weak especially about durability and color resistance. However before criticizing, everyone must self-criticize him/ herself and ask the question: if these direct restorations were done correctly or not? Like all dental procedures, direct composite resin restorations have some indications and contra-indications. These can be aliened as; proper occlusal relations [18], correct shade selection [19], good isolation [20], good adhesion [21], detailed polishing [22], frequent recalls [18,21] quality materials [18] and also clinical experience. These are like rings of a circle and if one of them breaks, then the whole restoration fails. If the direct composite resin restorations were performed by taking these into consideration, the success rate of these restorations would definitely increase.

\section{Conclusion}

As a conclusion although 2 years times still a short term to evaluate, with correct indication, quality material and proper technique the direct resin restorations were seemed to be highly long lasting, color resistant and aesthetic under the conditions of this follow-up case study. If direct restorations with composite resins are done by the rules, they are obviously one of the best treatment options for today's dentistry.

\section{References}

1. Terry DA, Leinfelder KF (2004) An integration of composite resin with natural tooth structure: The class IV restoration. Pract Proced Aesthet Dent 16(3): 235-242.

2. Lavigueur C, Zhu XX (2012) Recent advances in 25. The development of dental composite resins. RSC Adv 2: 59-63.

3. Azzaldeen A, Muhamad AH (2015) Diastema closure with direct composite: architectural gingival contouring. Journal of Advanced Medical and Dental Sciences Research 3(1): 134-139.

4. Jordan RE, Suzuki M (1992) The ideal composite material. J Can Dent Assoc 58(7): 528.

5. Moszner N, Salz U (2007) Recent developments of new components for dental adhesives and composites. Macromolecular Materials and Engineering 292(3): 245-271.

6. Aslam A, Ahmed B, Azad AA, Ovais N, Nayyer M, et al. (2016) Layers To A Beautiful Smile: Composite Resin Stratification. Pakistan Oral and Dental Journal 36(2). 
7. Dietschi D, Fahl N (2016) Shading concepts and layering techniques to master direct anterior composite restorations: an update. Br Dent J 221(12): 765-771.

8. Pecho OE, Pérez MM, Ghinea R, Della Bona A (2016) Lightness, chroma and hue differences on visual shade matching. Dent Mater 32(11): 1362-1373

9. Paschoal MA, Santos Pinto L, Nagle M, Ricci WA (2014) Esthetic and function improvement by direct composite resins and biomimetic concept. J Contemp Dent Pract 15(5): 654-658.

10. Carneiro PMA, Ramos TM, de Azevedo CS, de Lima E, de Souza SHJ, et al. (2016) Influence of Finishing and Polishing Techniques and Abrasion on Transmittance and Roughness of Composite Resins. Oper Dent 41(6): 634-641.

11. Abiodun Solanke IMF, Ajayi DM, Arigbede AO (2014) Nanotechnology and its application in dentistry. Ann Med Health Sci Res 4(suppl 3): 171-177.

12. Pahuja H, Mittal GK, Agarwal S, Verma A, Tomar H, et al. (2016) Restoring Esthetics in Fractured Anterior Teeth-Template Technique. Journal of Contemporary Medical Research 3(5): 1283-1284

13. Banerji S, Mehta SB (2017) The Finishing and Polishing of Resin Composite Restorations. Practical Procedures in Aesthetic Dentistry, p. 134.

14. Saen P, Atai M, Nodehi A, Solhi L (2016) Physical characterization of unfilled and nanofilled dental resins: Static versus dynamic mechanical properties. Dental Materials 32(8): 185-197.

15. Gurrea J, Gurrea M, Bruguera A, Sampaio CS, Janal M, et al, (2016) evaluation of dental shade guide variability using cross-polarized photography. Int J Periodontics Restorative Dent 36(5): e76-e81.
16. Miotti LL, Santos IS, Nicoloso GF, Pozzobon RT, Susin AH, et al. (2016) The use of resin composite layering technique to mask discolored background: A CIELAB/CIEDE2000 analysis. Oper Dent 42(2): 165-174.

17. Steinhaus J, Hausnerova B, Haenel T, Selig D, Duvenbeck F, et al. (2016) Correlation of shear and dielectric ion viscosity of dental resins-Influence of composition, temperature and filler content. Dental Materials 32(7): 899-907.

18. Korkut B, Yanıkoğlu F, Günday M (2013) Direct composite laminate veneers: three case reports. J Dent Res Dent Clin Dent Prospects 7(2): 105-111.

19. McLaren EA, Figueira J, Goldstein RE (2017) A Technique Using Calibrated Photography and Photoshop for Accurate Shade Analysis and Communication. Compendium of continuing education in dentistry 38(2): 106-113.

20. Loguercio AD, Luque Martinez I, Lisboa AH, Higashi C, Queiroz VO, et al. (2015) Influence of Isolation Method of the Operative Field on Gingival Damage, Patients' Preference and Restoration Retention in Noncarious Cervical Lesions. Oper dent 40(6): 581-593.

21. Chopade RV, Karade PM, Kulkarni AP, Bade KS, Lavate AB, et al. (2016) An Evaluation and Comparison of Shear Bond Strength of Two Adhesive Systems to Enamel and Dentin: An In Vitro Study. Journal of International Oral Health 8(1): 86-89.

22. Çelik N, Sağsöz Ö, Gündoğdu M (2017) Farklı içeceklerin posterior kompozitlerin renk değişikliği ve yüzey pürüzlülüğü üzerine etkisinin değerlendirilmesi 27(1): 27-33.

\section{Your next submission with Juniper Publishers} will reach you the below assets

- Quality Editorial service

- Swift Peer Review

- Reprints availability

- E-prints Service

- Manuscript Podcast for convenient understanding

- Global attainment for your research

- Manuscript accessibility in different formats

( Pdf, E-pub, Full Text, Audio)

- Unceasing customer service

Track the below URL for one-step submission https://juniperpublishers.com/online-submission.php 